\title{
Determining the Factors Affecting the Boiling Heat Transfer Coefficient of Sintered Coated Porous Surfaces
}

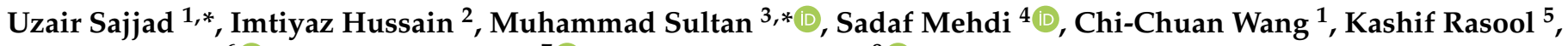 \\ Sayed M. Saleh ${ }^{6}$, Ashraf Y. Elnaggar ${ }^{7}$ (D) and Enas E. Hussein ${ }^{8}(\mathbb{D}$
}

1 Department of Mechanical Engineering, National Yang Ming Chiao Tung University, 1001 University Road, Hsinchu 300, Taiwan; ccwang@nctu.edu.tw

2 Department of Power Mechanical Engineering, National Tsing Hua University, No. 101, Section 2, Guangfu Road, East District, Hsinchu 300, Taiwan; imtiyazkou@yahoo.com

3 Department of Agricultural Engineering, Bahauddin Zakariya University, Bosan Road, Multan 60800, Pakistan

4 Department of Mechanical Engineering, Wichita State University, Wichita, KS 67260, USA; mehdi.sadaf96@gmail.com

5 Qatar Environment and Energy Research Institute, Hamad Bin Khalifa University (HBKU), Qatar Foundation, Doha P.O. Box 5825, Qatar; krasool@hbku.edu.qa

6 Department of Chemistry, College of Science, Qassim University, Buraidah 51452, Saudi Arabia; e.saleh@qu.edu.sa

7 Department of Food Nutrition Science, College of Science, Taif University, P.O. Box 11099, Taif 21944, Saudi Arabia; aynaggar@tu.edu.sa

8 National Water Research Center, P.O. Box 74, Shubra El-Kheima 13411, Egypt; enas_el-sayed@nwrc.gov.eg

* Correspondence: energyengineer01@gmail.com (U.S.); muhammadsultan@bzu.edu.pk (M.S.)

Citation: Sajjad, U.; Hussain, I.; Sultan, M.; Mehdi, S.; Wang, C.-C.; Rasool, K.; Saleh, S.M.; Elnaggar, A.Y.; Hussein, E.E. Determining the Factors Affecting the Boiling Heat Transfer Coefficient of Sintered Coated Porous Surfaces. Sustainability 2021, 13, 12631. https://doi.org/10.3390/

su132212631

Academic Editor: Cinzia Buratti

Received: 29 September 2021

Accepted: 4 November 2021

Published: 16 November 2021

Publisher's Note: MDPI stays neutral with regard to jurisdictional claims in published maps and institutional affiliations.

Copyright: (c) 2021 by the authors. Licensee MDPI, Basel, Switzerland. This article is an open access article distributed under the terms and conditions of the Creative Commons Attribution (CC BY) license (https:// creativecommons.org/licenses/by/ $4.0 /)$.

\begin{abstract}
The boiling heat transfer performance of porous surfaces greatly depends on the morphological parameters, liquid thermophysical properties, and pool boiling conditions. Hence, to develop a predictive model valid for diverse working fluids, it is necessary to incorporate the effects of the most influential parameters into the architecture of the model. In this regard, two Bayesian optimization algorithms including Gaussian process regression (GPR) and gradient boosting regression trees (GBRT) are used for tuning the hyper-parameters (number of input and dense nodes, number of dense layers, activation function, batch size, Adam decay, and learning rate) of the deep neural network. The optimized model is then employed to perform sensitivity analysis for finding the most influential parameters in the boiling heat transfer assessment of sintered coated porous surfaces on copper substrate subjected to a variety of high- and low-wetting working fluids, including water, dielectric fluids, and refrigerants, under saturated pool boiling conditions and different surface inclination angles of the heater surface. The model with all the surface morphological features, liquid thermophysical properties, and pool boiling testing parameters demonstrates the highest correlation coefficient, $\mathrm{R}^{2}=0.985$, for HTC prediction. The superheated wall is noted to have the maximum effect on the predictive accuracy of the boiling heat transfer coefficient. For example, if the wall superheat is dropped from the modeling parameters, the lowest prediction of $R^{2}(0.893)$ is achieved. The surface morphological features show relatively less influence compared to the liquid thermophysical properties. The proposed methodology is effective in determining the highly influencing surface and liquid parameters for the boiling heat transfer assessment of porous surfaces.
\end{abstract}

Keywords: pool boiling heat transfer coefficient; sintered coated porous surfaces; deep neural network; Bayesian optimization; gaussian process; gradient boosting regression trees

\section{Introduction}

Due to rapid advancements in the machining industry, microelectronics devices have gained popularity. These devices produce large amounts of heat. For the system safety and health of these devices, the removal of high heat fluxes in minimal space 
has become a challenge. These high heat fluxes cannot be handled by single-phase heat transfer. With the exploitation of latent heat, two-phase techniques are providing improved results, and several phase change phenomena are under investigation, for instance pool boiling, gas-assisted evaporative cooling, and spray cooling. Boiling heat transfer is a ubiquitous phenomenon because of its large heat-removing ability. Its applications are diverse, from renewable energy systems to refrigeration industries, desalination, nuclear reactors, and waste heat recovery plants. Similarly, if there is an uplift in the performance of the evaporator, it will be reflected in the efficiency of the heat pump. In the past decade, much research has been carried out to understand the boiling phenomenon.

Boiling heat transfer mainly depends on the surface and liquid thermophysical properties, and usually there are some constraints on the working fluid [1]. So, the best way to enhance the heat transfer is to modify the surface geometry [2]. Enhanced surfaces' morphologies can be changed by using various methods, broadly classified as active and passive techniques [2]. Surface engineering is performed to encourage rewetting, increase the nucleation sites, and improve the effective boiling surface area [3]. Advanced additive manufacturing technique are providing a great deal of flexibility in getting an optimized porous geometry, and many studies have been conducted on porous surfaces. As reported by researchers, the boiling performance of enhanced surfaces is improved due to the presence of a large number of bubble seeding cavities (nucleation sites), facilitating earlier and more numerous bubble detachment $[4,5]$. At the same time, porous substrates have also been able to extend the CHF limit by interrupting the bubbles' coalescence because of their having separate liquid-vapor paths, facilitating sustainable liquid replenishment [4]. Leonardo et al. [6] reported on two porous metal foams' ( $\mathrm{Ni}$ and $\mathrm{Cu}$ ) performances with respect to the heat flux. They found that copper foam showed significant improvement throughout the boiling curve as compared to the simple surface. They attributed this enhancement to the improved thermal conductivity of copper. Through visualization, they found that $\mathrm{Ni}$ foam successfully generated many small bubbles at low heat flux and reduced the ONB; however, at high heat flux, it resisted the early removal of large bubbles, which deteriorated the heat transfer.

Among various coated surfaces, sintered surfaces have shown promising results with higher stability [7]. Pastsuzko et al. [8] prepared sintered microporous surfaces and conducted visualization experimentation during the pool boiling of water and FC-72. They observed $130 \%$ and $75 \%$ enhancements in heat flux for water and Fc-72, respectively, with respect to the plain sample. Furthermore, they also developed a simple semi-analytical model to predict the boiling heat transfer. Halon et al. [9] tested the samples manufactured by Pastsuzko et al. [8] and analyzed the boiling behavior under sub-atmospheric conditions using water as the working fluid. They also observed enhancement in heat transfer. However, the best-performing sample under atmospheric conditions was the worst-performing under sub-atmospheric conditions. Arvind and Satish [10] created three boiling surfaces to analyze the microchannel performance with varied microporous coatings. During their tests, the maximum degree of enhancement was achieved by the sample with fully sintered microchannels as compared to the other two surfaces (only fin tops and channel walls). Xu et al. [11] investigated the role of the shape of the pore opening, coating thickness and thermal conductivity of the material during the pool boiling of DI water on open-celled metallic foam-sintered surfaces. They found that the sintered foam sample performed better than the grooved-shape surface because of the high pore density of the sintered foam structure. Moreover, the larger grooved samples' performance was poorer than the narrow-grooved one's because of the low capillary force of wide grooves. Jun et al. [12] conducted a parametric study of the pool boiling of water on sintered copper surfaces. They studied the particle sizes of $10 \mu \mathrm{m}, 25 \mu \mathrm{m}$ and $67 \mu \mathrm{m}$ with different coating thicknesses. They observed a plausible increase in heat transfer coefficient (HTC) and critical heat flux (CHF). As compared to the plain sample, the maximum enhancement in HTC was $8 \times$ at a particle size of $67 \mu \mathrm{m}$ with a coating thickness of $296 \mu \mathrm{m}$, and the highest reported improvement in CHF was $2 \times$ at the particle size of $67 \mu \mathrm{m}$ and coating 
thickness of $428 \mu \mathrm{m}$. Within their tested range, both HTC and CHF increased as the particle size or coating thickness increased. Another research group [13] prepared honeycomb porous structures with and without radial gradient by electrodeposition and sintering in a reducing environment. They tested the samples in the pool boiling of DI water and found that the samples with radial gradient, and smaller pores at the center than near the edges, showed better heat transfer than the sample with uniform structure. They attributed this enhancement to the higher $\mathrm{K} /$ Reff, and as per their investigation, a radial gradient from edges to center assisted in quicker rewetting. Furthermore, through visualization experimentation, they also found that the radially distributed porous sample generated larger bubbles at a faster rate, which helped in removing more heat than in other samples. Recently, Pastsuzko et al. [14] investigated the boiling heat transfer of water, FC-72 and Novec-649 on microporous sintered surfaces with and without mesh. They postulated that mesh coverings on the sintered micro-finned surfaces are only effective at low heat flux for liquids with low surface tension, because at the high heat flux $\left(50 \mathrm{~kW} / \mathrm{m}^{2}\right.$ for FC-72 and $100 \mathrm{~kW} / \mathrm{m}^{2}$ for ethanol), maximum performance was recorded in the sample with no mesh or covering.

\section{Aim and Motivation of the Study}

As reported by researchers, porous surfaces' performance greatly depends on the morphological parameters, and these parameters are affected by changes in the working fluid. So, to develop a predictive model valid for diverse working fluids, it is necessary to incorporate the effect of these parameters and the thermophysical properties of the working fluid. The predictability of the empirical correlations is usually hampered by these parameters, because these correlations were developed on a limited database. To cover a wide range of data, an artificial intelligence (AI) model, based on advance algorithms and new libraries, can be developed with high accuracy [1,15]. Keeping this in view, the objective of this study is to develop Bayesian optimized deep neural network models to perform a sensitivity analysis for finding the most influential parameters in the boiling heat transfer of sintered coated porous surfaces fabricated on copper substrate, subjected to a variety of high- and low-wetting working fluids, including water, dielectric fluids, and refrigerants, under saturated pool boiling conditions and different surface inclination angles of the heater surface. The detailed impacts of combined and individual surfaces, liquids, and boiling condition parameters have been assessed for a range of tested data. In line with this, the most impactful parameters are highlighted by representing their predictions. The proposed method can help to assess the strong morphological parameters of sintered coated porous surfaces subjected to a range of working fluids and pool boiling conditions. The proposed methodology is effective in determining the highly influential surface and liquid parameters for boiling heat transfer assessment.

\section{Materials and Methods}

\subsection{Experimental Data Collection}

In the present investigation, 380 data points have been collected from the saturated pool boiling experiments of microporous coated surfaces for different high- and low-surface tension working fluids including water, dielectric liquids, and refrigerants [11,12,14,16-34]. Most of the tested porous surfaces are manufactured by sintering techniques. The considered porous surfaces have a range of morphological parameters in terms of particle diameter, surface roughness, coating thickness, and porosity. The considered data include the saturated pool boiling results for a variety of surface inclination angles $\left(0-180^{\circ}\right)$. The investigated wall superheat is $0-40 \mathrm{~K}$ and the heat transfer coefficient ranges between 0.5 and $476 \mathrm{~kW} / \mathrm{m}^{2} \mathrm{~K}$. The experimental data range of the studied parameters can be seen in Table 1. 
Table 1. Investigated experimental data range.

\begin{tabular}{ccc}
\hline Parameter & Value & Unit \\
\hline Wall Superheat & $0.5-38$ & $\mathrm{~K}$ \\
HTC & $0.45-476$ & $\mathrm{~kW} \mathrm{~m}^{-2} \mathrm{~K}^{-1}$ \\
Heat Flux & $0.3-18088$ & $\mathrm{~kW} \mathrm{~m}^{-2}$ \\
Surface Inclination & $0-180$ & $\circ$ \\
Saturation Temperature & $56-100$ & ${ }^{\circ} \mathrm{C}$ \\
Liquid Density & $997-1680$ & $\mathrm{Kg} \mathrm{m}^{-3}$ \\
Heat of Vaporization & $88-2257$ & $\mathrm{~kJ} \mathrm{~kg}^{-1}$ \\
Specific Heat & $1100-4180$ & $\mathrm{~J} \mathrm{Kg}^{-1} \mathrm{~K}^{-1}$ \\
Surface Tension & $10-72$ & $\mathrm{~m} \mathrm{Nm}^{-1}$ \\
Porosity & $0.057-0.608$ & $\mathrm{~W} \mathrm{~m}^{-1} \mathrm{~K}^{-1}$ \\
Thermal Conductivity of the Working Fluid & $39-65$ & $\%$ \\
Particle Diameter & $11.2-1000$ & $\mu \mathrm{m}$ \\
Coating Thickness & $250-590$ & $\mu \mathrm{m}$ \\
\hline
\end{tabular}

\subsection{Methodology}

Training and testing data are divided $80-20 \%$ as is commonly practiced in the literature $[35,36]$. Firstly, two models were developed by considering the surface parameters, liquid thermophysical features, and surface inclination angle. In one of the models, other than the aforementioned parameters, heat flux was taken as the added input parameter, while in the second model, wall superheat was taken as the added input parameter. It was noticed that the wall superheat model showed much better prediction ability compared to the heat flux model. Based on these findings, we decided to consider the wall superheat model for the further assessment of boiling heat transfer coefficient.

\subsubsection{Bayesian Optimization (BO)}

Bayesian optimization is used to select the hyper-parameters for evaluation in the true objective function by building a probability model of the objective function. This employs the Bayes theorem for determining the maximum and minimum of an objective function. There are different techniques available based on the BO. Here, the two most common BO methods, GPR and GBRT, are considered for hyper-parameter optimization.

\subsubsection{Gaussian Process Regression (GPR)}

The GPR model is an ML framework employed for classification and regression problems. This is a nonparametric Bayesian method for regression. GPR can work well for small databanks. The GPR model predicts by including prior knowledge, and provides predictions uncertainty measures.

\subsubsection{Gradient Boosting Regression Trees (GBRT)}

Decision trees are machine learning algorithms that are most famous for their feature selection. These can be used for classification and regression problems. Decision trees for regression problems are known as regression trees. The model starts learning with an increase in the iterations. The training process stops when the hyper-parameters are triggered. GBRTs are iterative algorithms in which each tree takes account of the error in the previous one, and their final outcome is the mean of all trees' predictions.

These algorithms require comparatively less effort in preprocessing data, and can process incomplete data. However, they are expensive in terms of the computational training time.

In order to achieve the optimized deep learning model, the hyper-parameters were tuned by using the Bayesian optimization method. Here, two different Bayesian optimization methods, namely, Gaussian process regression (GPR) and gradient boosting regression trees (GBRT), were used for hyper-parameter tuning. For the models' performance evalua- 
tion, different error metrics, such as the correlation coefficient $\left(\mathrm{R}^{2}\right)$, mean absolute error (MAE), and absolute average relative deviation (AARD), were used.

Figure $1 \mathrm{a}, \mathrm{b}$ represents the procedure and flow charts for fine-tuning the hyperparameters by using two different Bayesian optimization methods, such as GPR and GBRT.

(a)

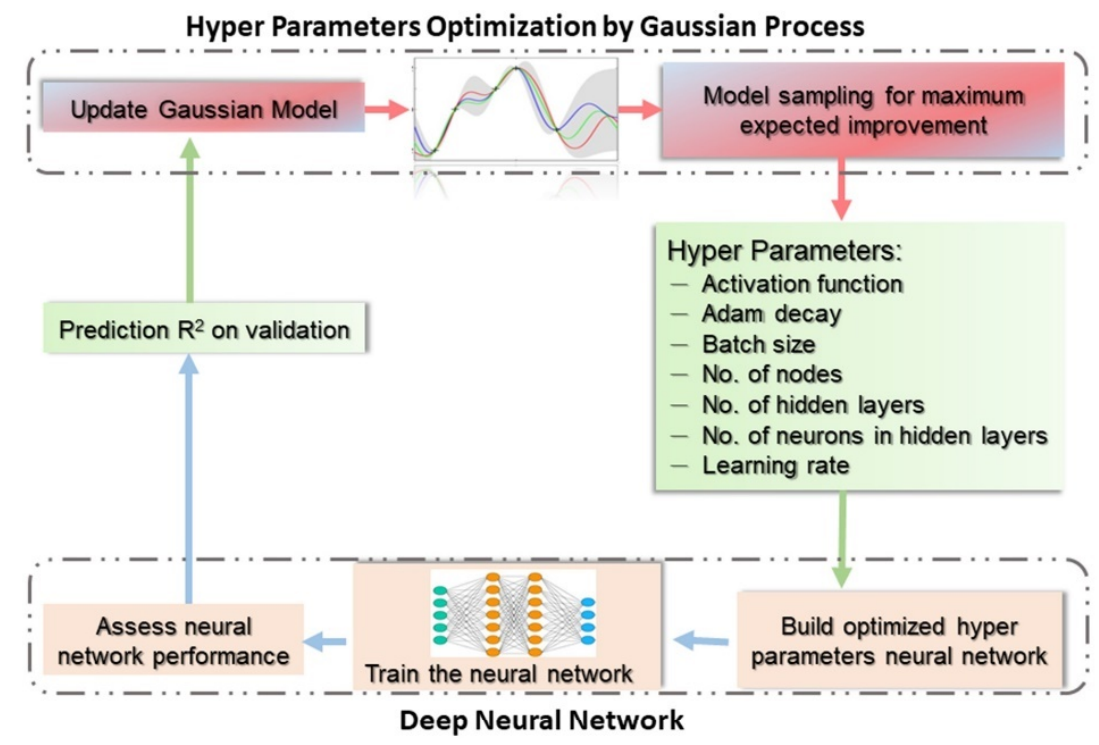

(b)

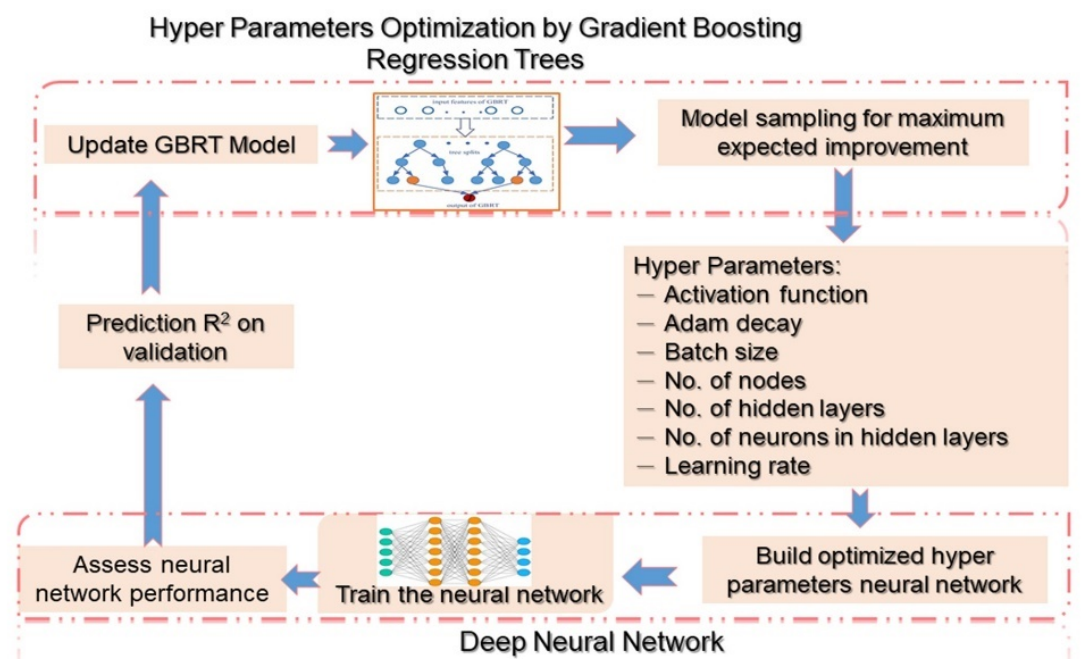

Figure 1. Procedure of hyper-parameter tuning by (a) Gaussian process and (b) gradient boosting regression trees.

Once the hyper-parameters are optimized, then a deep neural network was developed based on the acquired information of the optimized hyper-parameters.

\subsubsection{Hyper-Parameters}

These are the parameters whose values are used in controlling the learning process. In order to achieve an optimal model with a short computational time, the hyper-parameters tuning should be optimized, which is a major goal of the BO. In the developed model, the hyper-parameters are activation function, learning rate, Adam decay, number of nodes, no. of hidden layers, no. of neurons in each hidden layer, and batch size, as shown in Figure 1. A pair plot showing the fine-tuned hyper-parameter can be seen in Figure 2. The red circles represent the optimal value for each hyper-parameter. In Figure 2, the yellow region shows a strong relationship (those values can be selected for the hyper-parameter) while the green region represents a weak relationship (those values are not recommended for selection of 
that hyper-parameter). The optimal hyper-parameters in terms of the partial dependence are highlighted in Figure 2. It can be seen that the no. of dense layers should be 6, the activation function should be ReLU, and so on. The range of hyper-parameters considered in this study can be witnessed in Table 2.

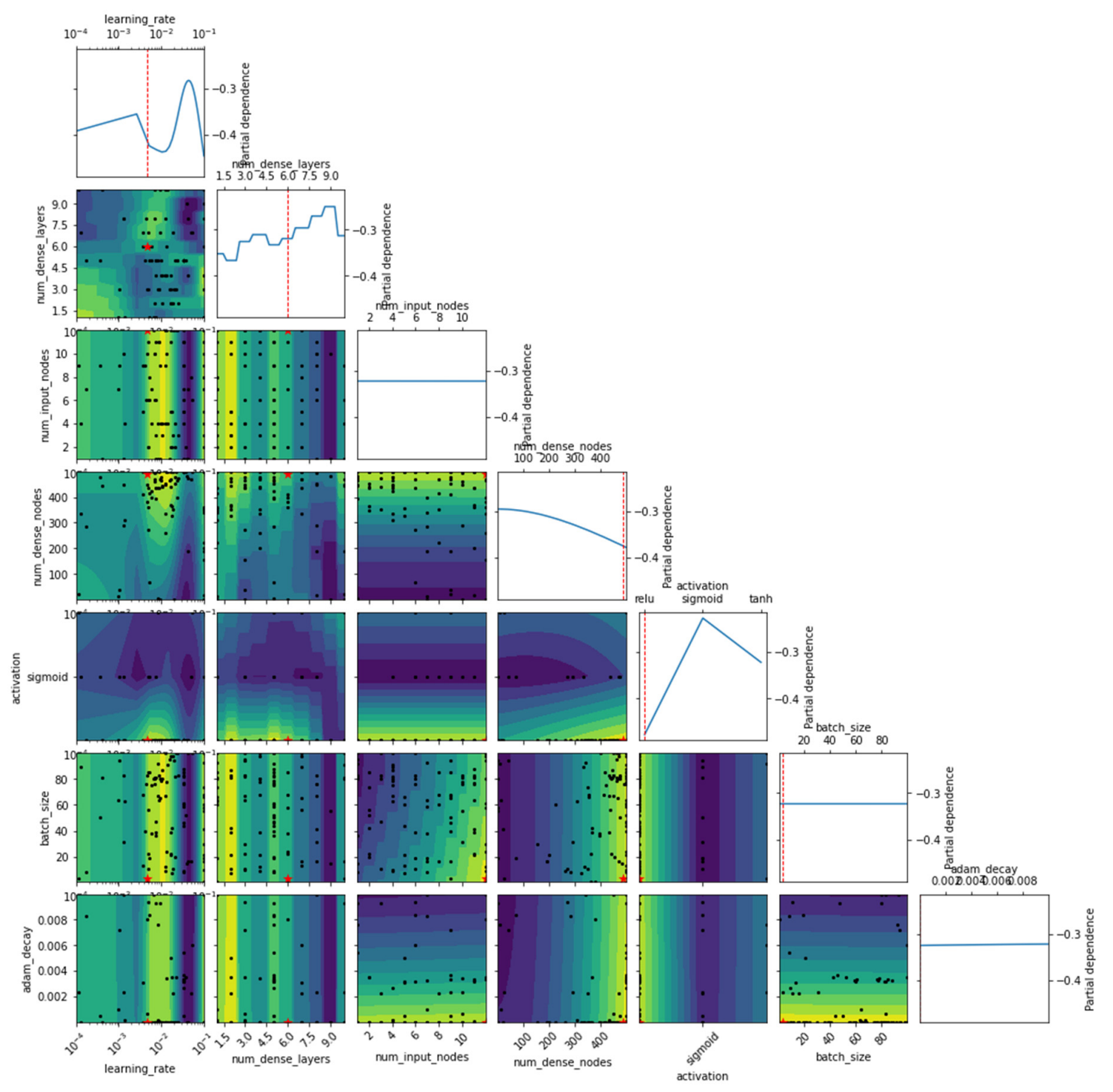

Figure 2. Pair plot showing the fine-tuned hyper-parameters.

Table 2. Range of hyper-parameters considered in this study.

\begin{tabular}{cc}
\hline Hyper-Parameter & Range \\
\hline Learning rate & 0.0001 to 0.1 \\
Adam decay & 0.000001 to 0.01 \\
Input nodes & 1 to 12 \\
Dense layers & 1 to 10 \\
Dense nodes & 1 to 500 \\
Batch size & 1 to 100 \\
Activation function & ReLU, Sigmoid, tanh \\
\hline
\end{tabular}

The method for achieving the best solution and minimizing the error with respect to the number of calls can be seen in Figure 3. It is obvious that the error reaches a minimum level after 40 calls, although the full convergence occurs at the 18th iteration. This represents 
the potential of the Bayesian optimization technique when considering a large number of input variables for a wide range of data. For instance, timely convergence was achieved for an optimal solution. The architecture of the optimized models is provided in Table 3, which clearly shows that both of the Bayesian optimization techniques, GPR and GBRT, yield the same values of correlation coefficient (R2). Other details regarding learning rate, no. of input and dense nodes, activation function, batch size, Adam decay, and no. of dense layers for both of the algorithms, can be found in Table 3.

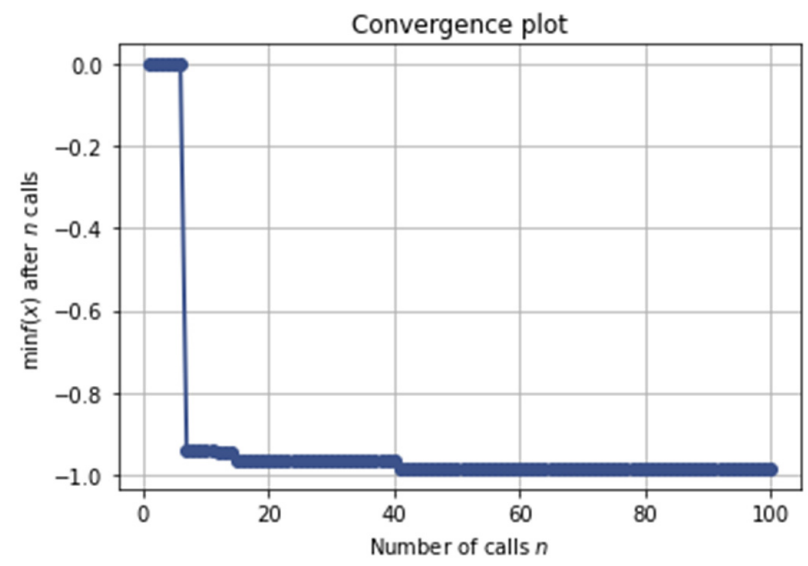

Figure 3. Error convergence plot.

Table 3. Architecture of the optimized models.

\begin{tabular}{ccc}
\hline Bayesian Optimization Method & Gradient Boosting Regression Trees & Gaussian Process \\
\hline Learning rate & 0.00787965 & 0.004673739 \\
No. of hidden layers & 6 & 6 \\
No. of neurons in input layer & 12 & 12 \\
No. of neurons in each hidden layer & 467 & 489 \\
Activation function & ReLU & ReLU \\
Batch size & 19 & 3 \\
Adam decay & 0.0048345 & 0.000001 \\
No. of neurons in output layer & 1 & 1 \\
Correlation coefficient $\left(\mathrm{R}^{2}\right)$ & 98.48 & 98.48 \\
\hline
\end{tabular}

\section{Results and Discussions}

Factors Affecting the Boiling Heat Transfer Coefficient

Pool boiling heat transfer mainly relies on the surface morphological features, liquid thermophysical properties, and pool boiling testing conditions (see Figure 4).

Generally, the porosity of a material is defined by the ratio of void volume to total volume, and various hypotheses about the influence of porosity on the boiling surface have been reported, for instance it can influence the heat transfer through the thickness of the porous coating, the diameter of the coating particles, the number of pores, and pore connectivity. By increasing the porosity, the wetted area is increased, and more nucleation sites become active as it becomes easier to supply the liquid to the nucleation sites, and this increases the number of bubbles and the bubble generation frequency, which result in heat transfer enhancement. At low heat fluxes, boiling performance is improved with the addition of the porous coated layer because of the formation of a large number of bubbles. However, at high heat flux, increases in coating thickness may result in the formation of a vapor blanket and heat transfer deterioration, and this is why the ratio of the coating thickness to particle diameter is calculated and an optimal value is reported [37]. Furthermore, the heat transfer coefficient can also be augmented by increasing the roughness of the boiling surface. This effect was reported for the first time by Jackob in 1931 [38]. A surface is roughened to create bubbles' seeding cavities in order to produce a large number of bubbles, and due to this, the heat transfer coefficient is improved [39,40]. 


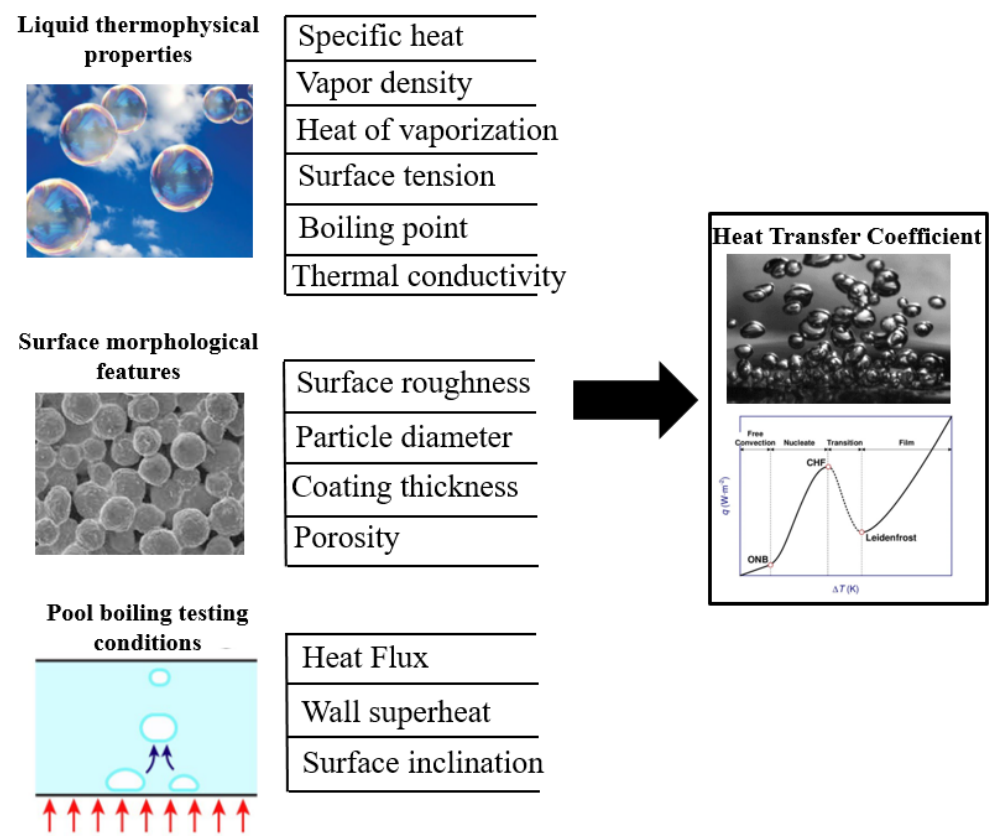

Figure 4. Parameters affecting the boiling heat transfer coefficient.

Some of the most influential liquid thermophysical properties in boiling heat transfer are liquid density, specific heat, vapor density, the latent heat of vaporization, surface tension, boiling point, and liquid thermal conductivity. Similarly, for microporous coated surfaces, the morphological parameters of porosity, coating thickness, particle diameter, and surface roughness have a strong influence on the boiling heat transfer coefficient.

The surface morphological parameters affecting the boiling heat transfer coefficient or porous surfaces are porosity, coating thickness, particle diameter, and surface roughness. The impact of individual morphological parameter on the boiling heat transfer assessment of various working fluids is provided in Figure 5, followed by the error density analysis in Figure 6. The impact of liquid thermophysical properties on the BHTC prediction along with error density analysis is given in Figures 7 and 8, while Figure 9 shows the sensitivity analysis of surface inclination and wall superheat.

Table 4 presents the individual and combined impacts of surface morphological features, liquid thermophysical properties, and pool boiling conditions on the assessment of heat transfer coefficient. Apparently, the model with all the surface morphological features, liquid thermophysical properties, and pool boiling testing parameters demonstrated the highest accuracy for HTC prediction. The wall superheat is noted to have the maximum impact on the predictive accuracy of the boiling heat transfer coefficient. More specifically, if the wall superheat is dropped from the modeling parameters, the lowest predictive $\mathrm{R}^{2}$ $(0.893 \%)$ is achieved. Among the surface morphological parameters, the particle diameter exhibits the strongest influence on the heat transfer coefficient. On the contrary, the surface roughness and coating thickness do not seem to have a strong impact on the pool boiling data of sintered coated porous surfaces for water, refrigerants, and dielectric liquids. In general, the surface features show relatively less influence compared to the liquid thermophysical properties. This is because liquids with totally different thermophysical properties result in very different boiling phenomena. However, liquid thermal conductivity and specific heat cause a noticeable impact on the boiling heat transfer coefficient of porous surfaces. From the above results, it can be stated that liquid thermophysical properties have much more of an effect on the pool boiling phenomenon of sintered coated porous surfaces compared to the morphology of the heater surfaces. In addition, the BHTC is strongly influenced by the surface inclination angle of the heater surface. 


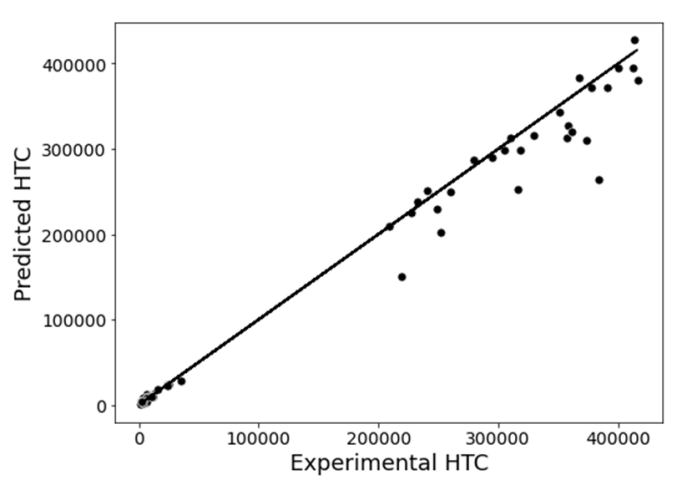

(a)

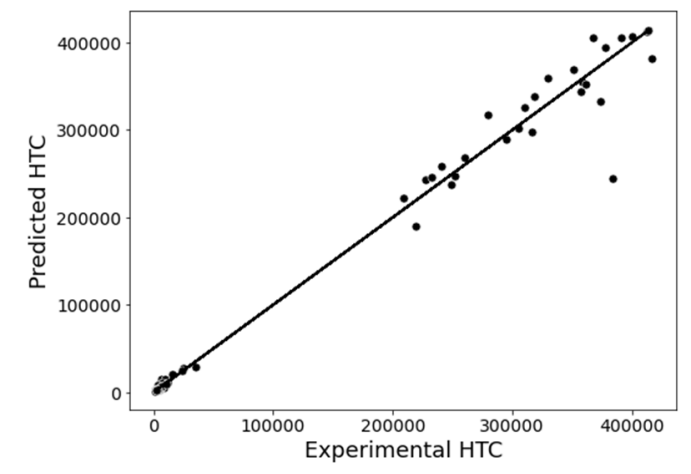

(c)

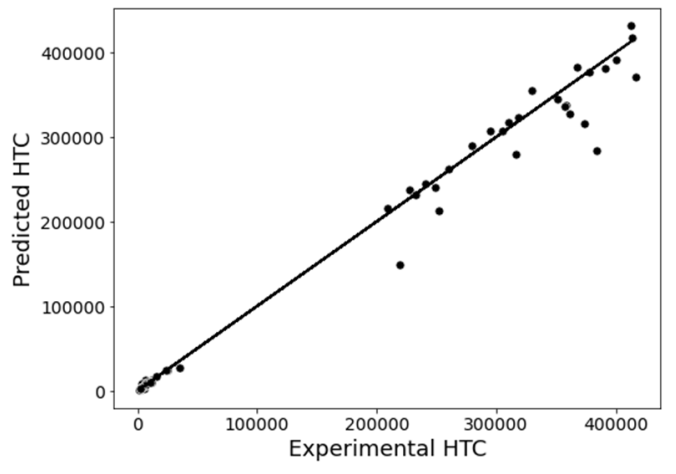

(e)

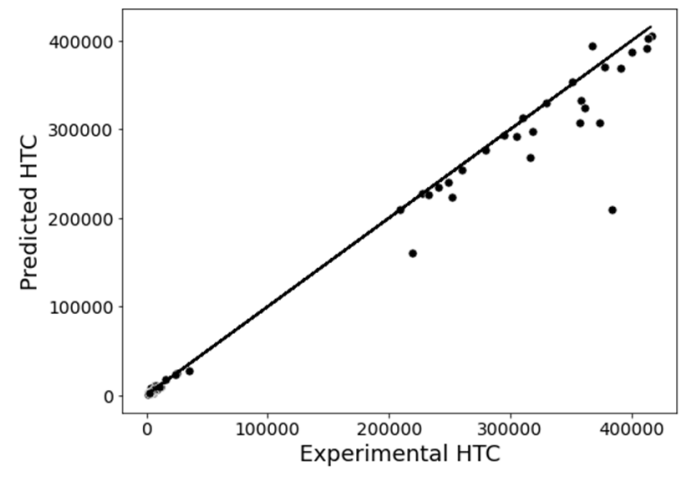

(b)

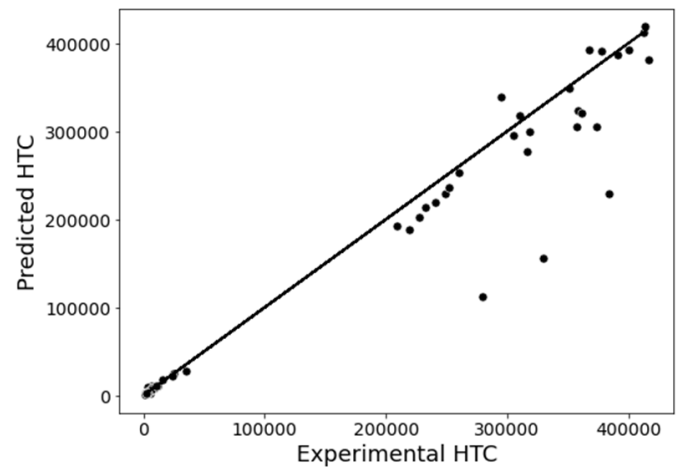

(d)

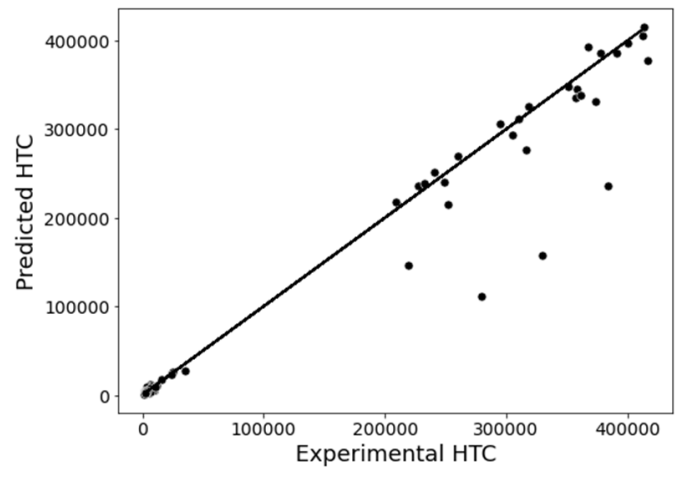

(f)

Figure 5. Impact of surface morphological features on the BHTC prediction. (a) Roughness dropped. (b) Porosity dropped. (c) Coating thickness dropped. (d) Particle diameter dropped. (e) Original with all features. (f) No surface feature.

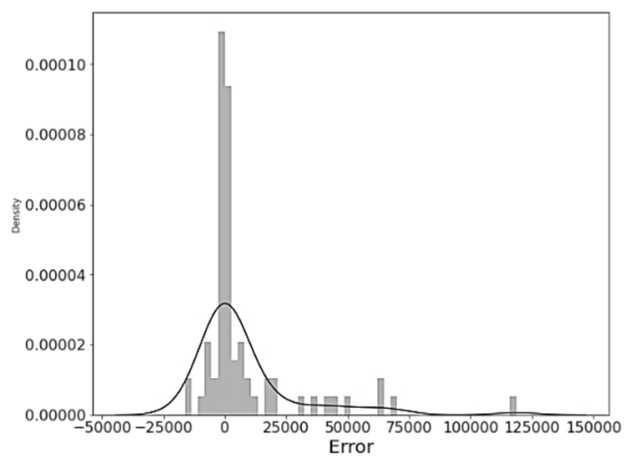

(a)

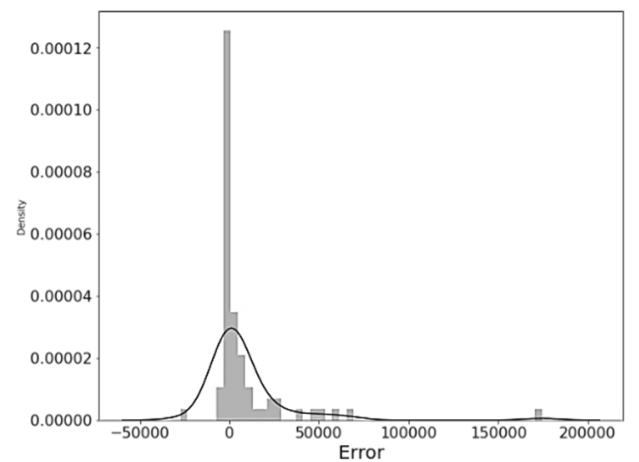

(b)

Figure 6. Cont. 


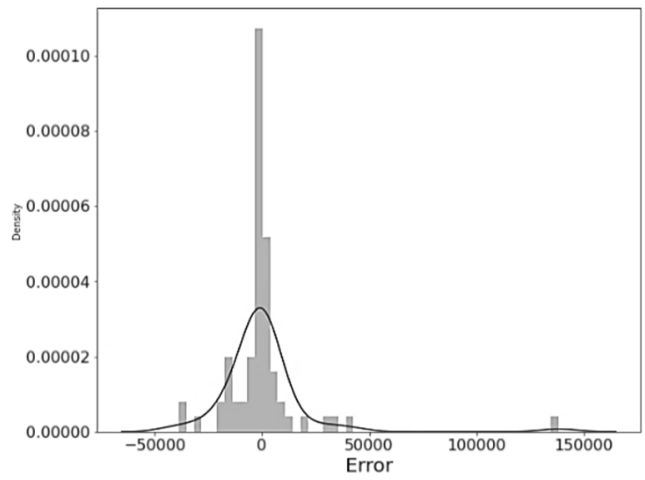

(c)

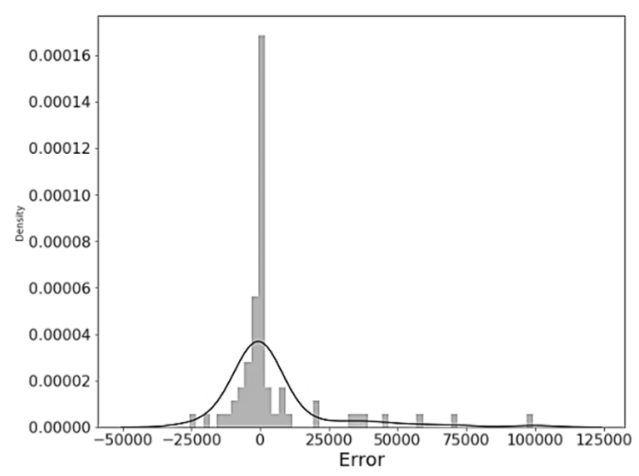

(e)

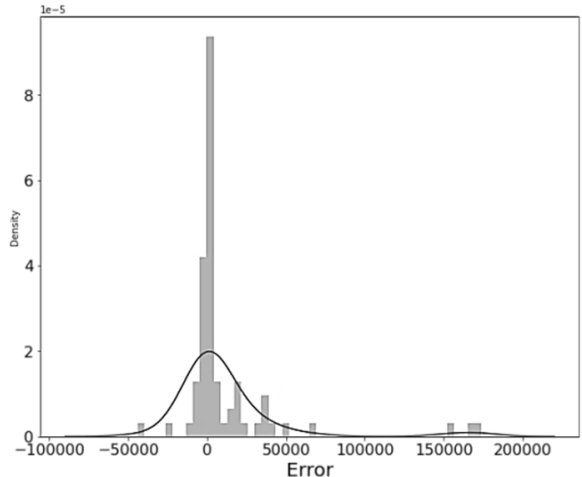

(d)

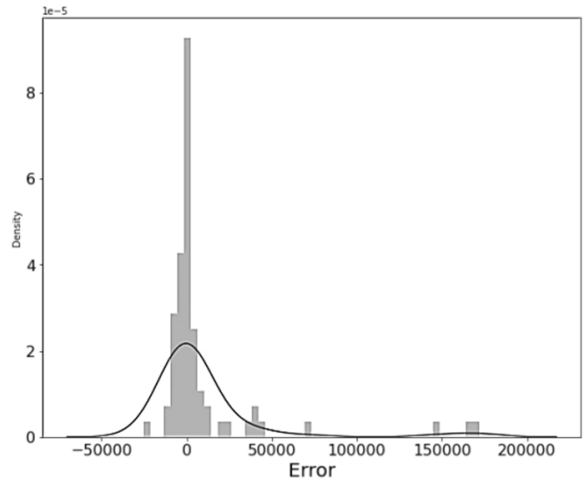

(f)

Figure 6. Error density analysis for surface morphological features in the BHTC prediction. (a) Roughness dropped. (b) Porosity dropped. (c) Coating thickness dropped. (d) Particle diameter dropped. (e) Original with all features. (f) All surface features dropped.

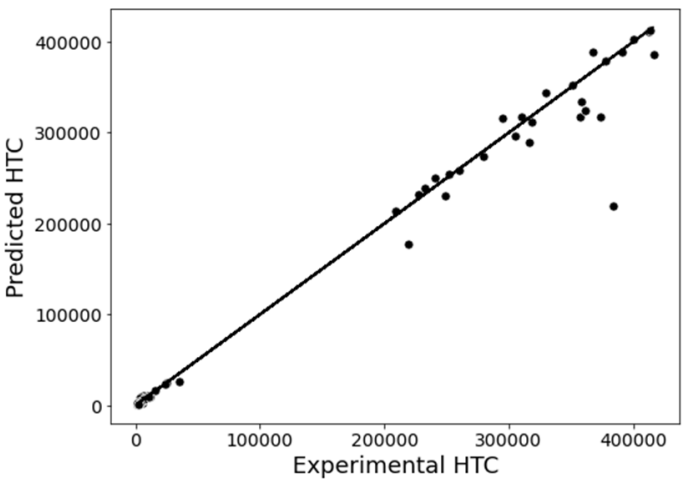

(a)

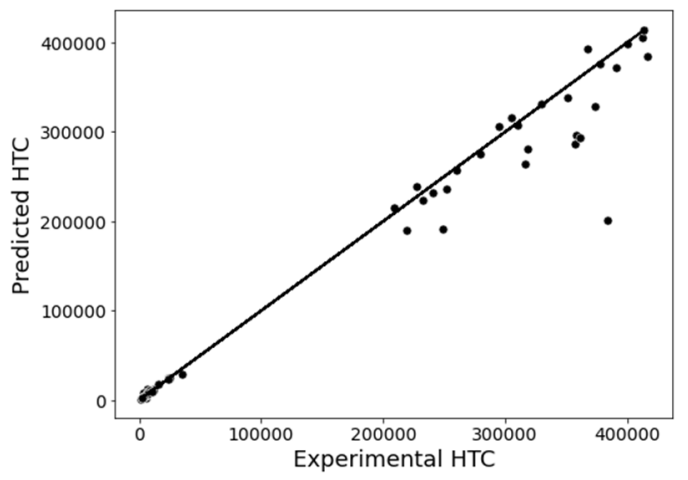

(c)

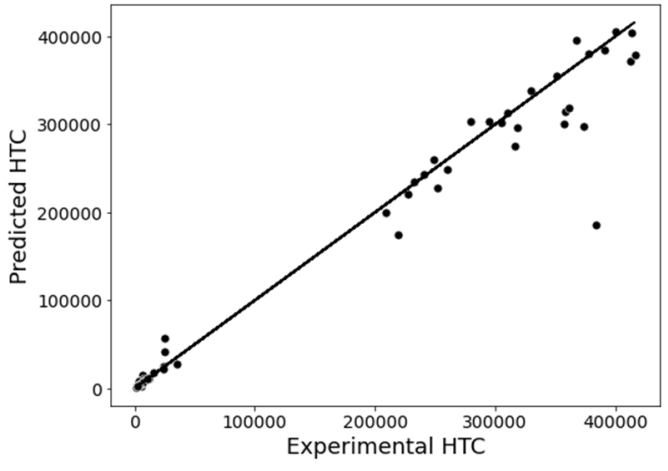

(b)

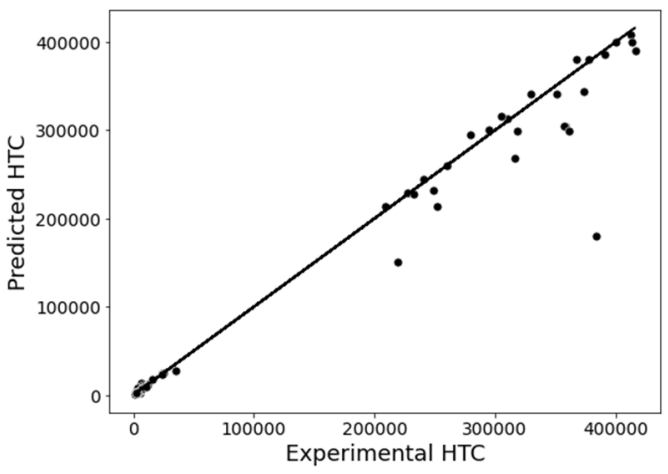

(d)

Figure 7. Cont. 


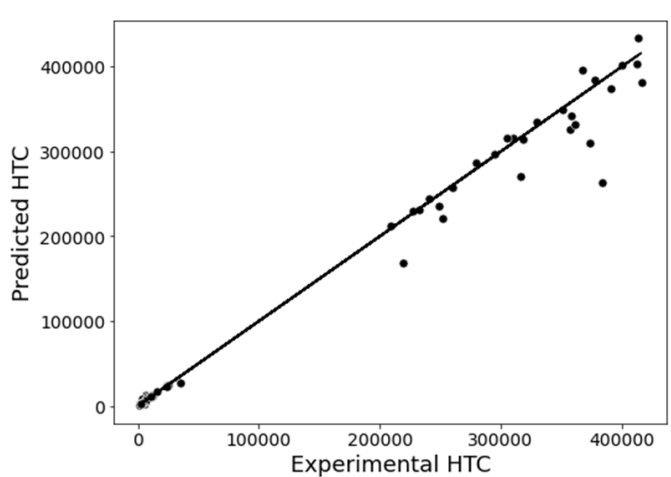

(e)

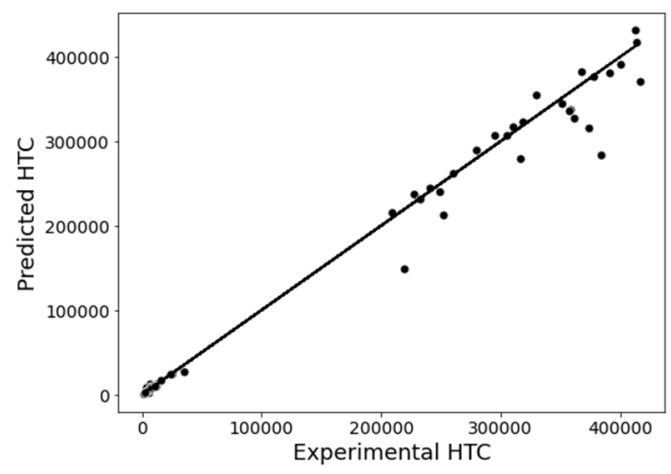

(g)

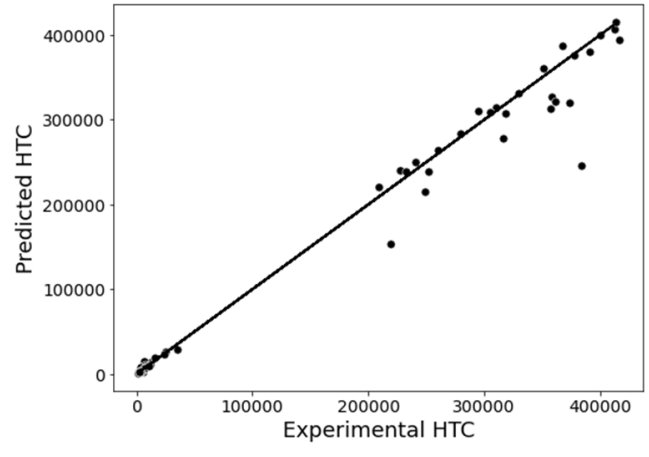

(f)

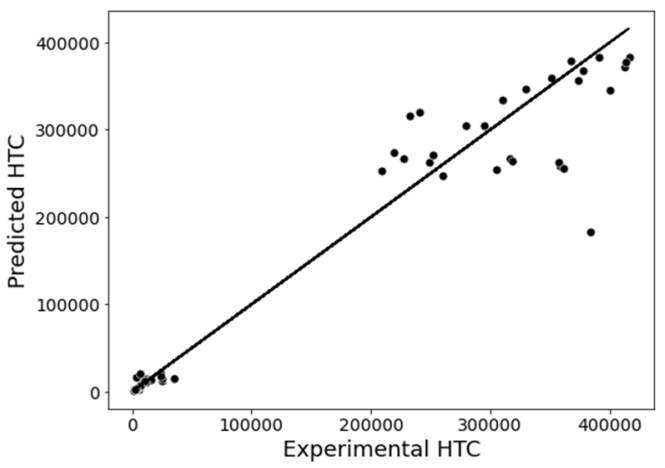

(h)

Figure 7. Impact of liquid thermophysical properties on the BHTC prediction. (a) Surface tension dropped. (b) Boiling point dropped. (c) Liquid density dropped. (d) Heat of vaporization dropped. (e) Specific heat dropped. (f) Liquid thermal conductivity dropped. (g) Original with all features. (h) No liquid properties.

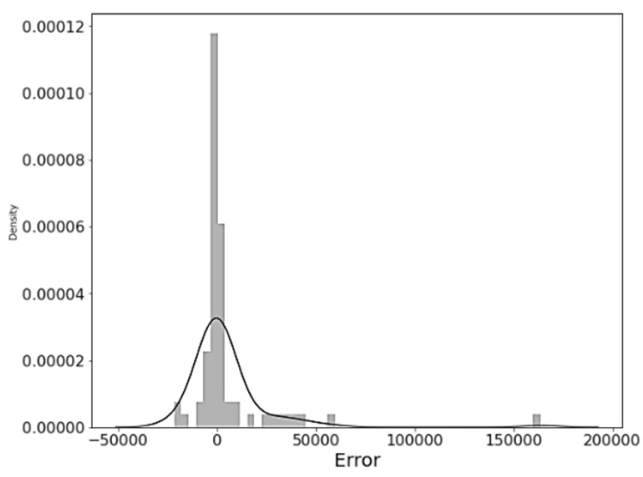

(a)

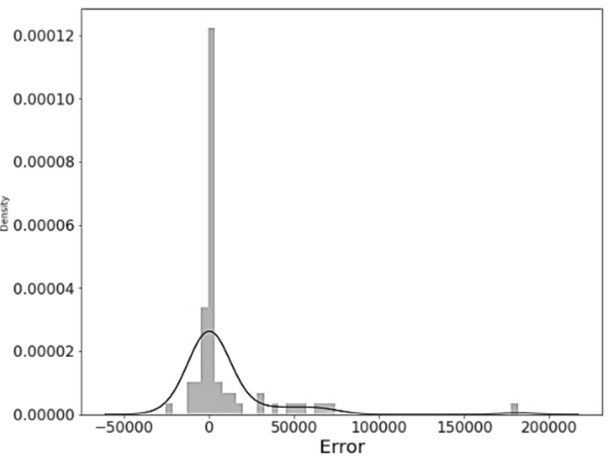

(c)

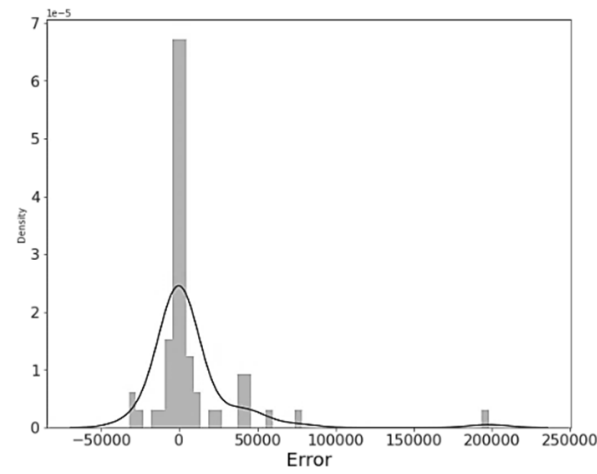

(b)

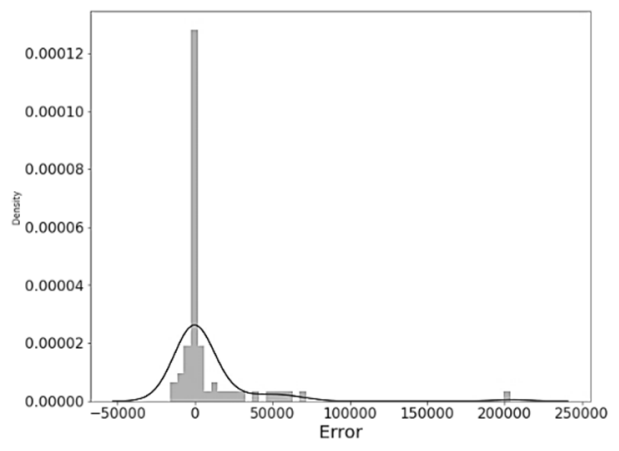

(d)

Figure 8. Cont. 


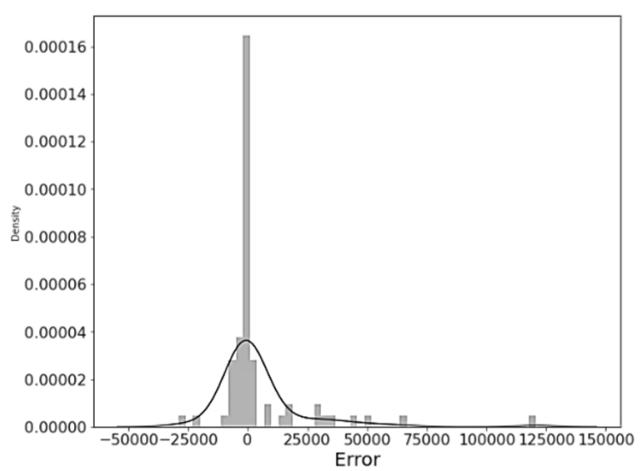

(e)

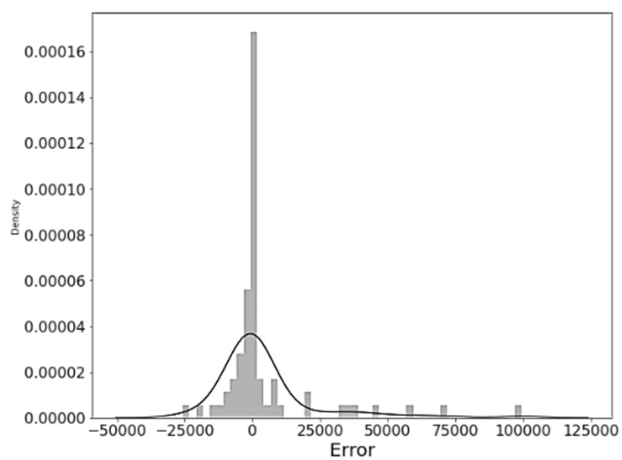

(g)

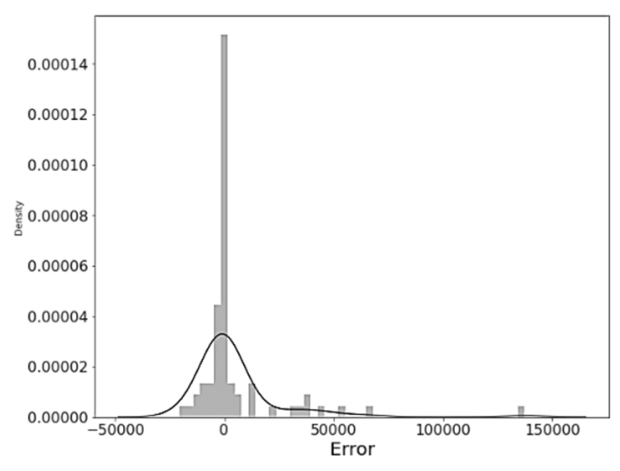

(f)

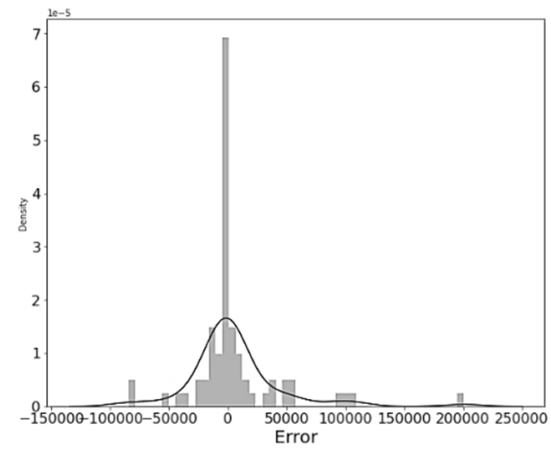

(h)

Figure 8. Error density analysis of liquid thermophysical properties in the BHTC prediction. (a) Surface tension dropped. (b) Boiling point dropped. (c) Liquid density dropped. (d) Heat of vaporization dropped. (e) Specific heat dropped. (f) Liquid thermal conductivity dropped. (g) Original with all features. (h) All liquid properties dropped.

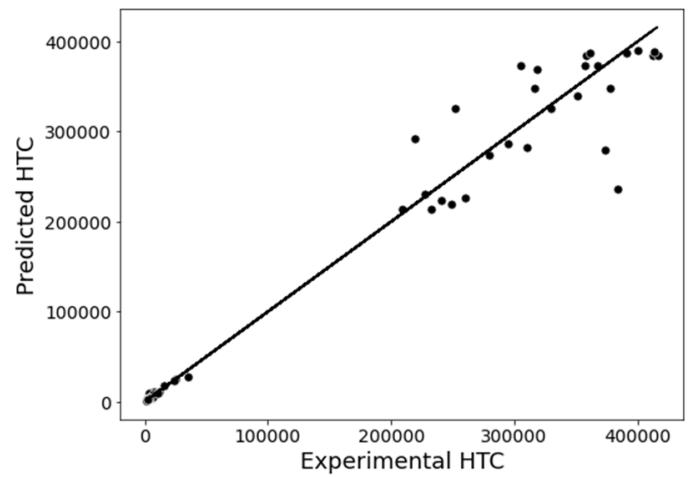

(a)

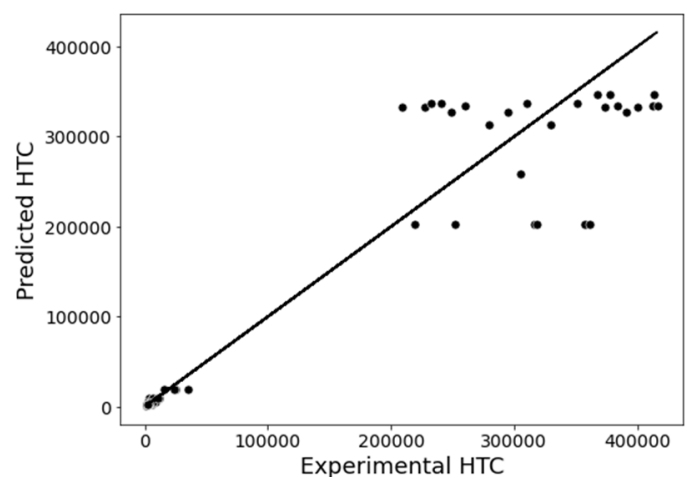

(b)

Figure 9. Cont. 


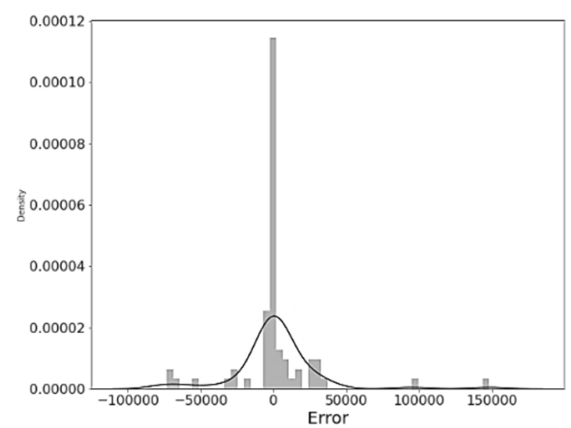

(c)

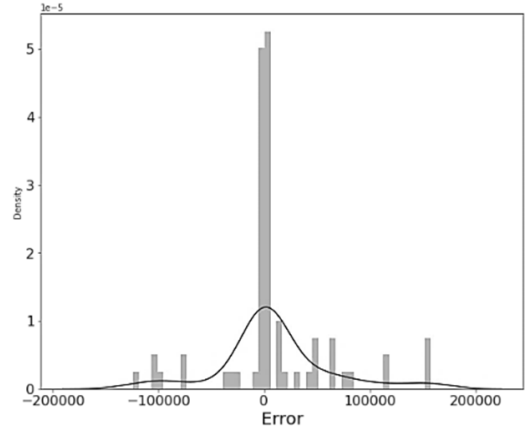

(d)

Figure 9. Impact of (a) surface inclination, (b) wall superheat and error density analysis of (c) surface inclination and (d) wall superheat in the BHTC prediction.

Table 4. Input parameters of the developed models along with their performances.

\begin{tabular}{|c|c|c|c|}
\hline Model & Input Parameters & $R^{2}$ & AARD \\
\hline $\begin{array}{l}\text { Original model with } \\
\text { all features }\end{array}$ & $\begin{array}{c}\text { porosity } \\
\text { coating thickness } \\
\text { particle diameter } \\
\text { surface roughness } \\
\text { liquid density } \\
\text { specific heat } \\
\text { latent heat of vaporization } \\
\text { surface tension } \\
\text { boiling point } \\
\text { liquid thermal conductivity } \\
\text { surface inclination } \\
\text { wall superheat }\end{array}$ & 0.9855 & 17.127 \\
\hline Porosity dropped & $\begin{array}{l}\text { coating thickness } \\
\text { particle diameter } \\
\text { surface roughness } \\
\text { liquid density } \\
\text { specific heat } \\
\text { latent heat of vaporization } \\
\text { surface tension } \\
\text { boiling point } \\
\text { liquid thermal conductivity } \\
\text { surface inclination } \\
\text { wall superheat }\end{array}$ & 0.975 & 16.301 \\
\hline $\begin{array}{l}\text { Coating thickness } \\
\text { dropped }\end{array}$ & $\begin{array}{c}\text { porosity } \\
\text { particle diameter } \\
\text { surface roughness } \\
\text { liquid density } \\
\text { specific heat } \\
\text { latent heat of vaporization } \\
\text { surface tension } \\
\text { boiling point } \\
\text { liquid thermal conductivity } \\
\text { surface inclination } \\
\text { wall superheat }\end{array}$ & 0.983 & 19.25 \\
\hline
\end{tabular}


Table 4. Cont.

\begin{tabular}{|c|c|c|c|}
\hline Model & Input Parameters & $\mathbf{R}^{2}$ & AARD \\
\hline $\begin{array}{l}\text { Particle diameter } \\
\text { dropped }\end{array}$ & $\begin{array}{c}\text { porosity } \\
\text { coating thickness } \\
\text { surface roughness } \\
\text { liquid density } \\
\text { specific heat } \\
\text { latent heat of vaporization } \\
\text { surface tension } \\
\text { boiling point } \\
\text { liquid thermal conductivity } \\
\text { surface inclination } \\
\text { wall superheat }\end{array}$ & 0.948 & 19.41 \\
\hline $\begin{array}{l}\text { Surface roughness } \\
\text { dropped }\end{array}$ & $\begin{array}{c}\text { porosity } \\
\text { coating thickness } \\
\text { particle diameter } \\
\text { liquid density } \\
\text { specific heat } \\
\text { latent heat of vaporization } \\
\text { surface tension } \\
\text { boiling point } \\
\text { liquid thermal conductivity } \\
\text { surface inclination } \\
\text { wall superheat }\end{array}$ & 0.981 & 22.088 \\
\hline $\begin{array}{c}\text { All surface features } \\
\text { dropped }\end{array}$ & $\begin{array}{c}\text { liquid density } \\
\text { specific heat } \\
\text { latent heat of vaporization } \\
\text { surface tension } \\
\text { boiling point } \\
\text { liquid thermal conductivity } \\
\text { surface inclination } \\
\text { wall superheat }\end{array}$ & 0.951 & 25.541 \\
\hline $\begin{array}{l}\text { Liquid density } \\
\text { dropped }\end{array}$ & $\begin{array}{c}\text { porosity } \\
\text { coating thickness } \\
\text { particle diameter } \\
\text { surface roughness } \\
\text { specific heat } \\
\text { latent heat of vaporization } \\
\text { surface tension } \\
\text { boiling point } \\
\text { liquid thermal conductivity } \\
\text { surface inclination } \\
\text { wall superheat }\end{array}$ & 0.969 & 15.678 \\
\hline Specific heat dropped & $\begin{array}{c}\text { porosity } \\
\text { coating thickness } \\
\text { particle diameter } \\
\text { surface roughness } \\
\text { liquid density } \\
\text { latent heat of vaporization } \\
\text { surface tension } \\
\text { boiling point } \\
\text { liquid thermal conductivity } \\
\text { surface inclination } \\
\text { wall superheat }\end{array}$ & 0.984 & 15.981 \\
\hline
\end{tabular}


Table 4. Cont.

\begin{tabular}{|c|c|c|c|}
\hline Model & Input Parameters & $\mathbf{R}^{2}$ & AARD \\
\hline $\begin{array}{c}\text { Heat of vaporization } \\
\text { dropped }\end{array}$ & $\begin{array}{c}\text { porosity } \\
\text { coating thickness } \\
\text { particle diameter } \\
\text { surface roughness } \\
\text { liquid density } \\
\text { specific heat } \\
\text { surface tension } \\
\text { boiling point } \\
\text { liquid thermal conductivity } \\
\text { surface inclination } \\
\text { wall superheat }\end{array}$ & 0.967 & 18.039 \\
\hline $\begin{array}{l}\text { Surface tension } \\
\text { dropped }\end{array}$ & $\begin{array}{c}\text { porosity } \\
\text { coating thickness } \\
\text { particle diameter } \\
\text { surface roughness } \\
\text { liquid density } \\
\text { specific heat } \\
\text { latent heat of vaporization } \\
\text { boiling point } \\
\text { liquid thermal conductivity } \\
\text { surface inclination } \\
\text { wall superheat }\end{array}$ & 0.979 & 16.932 \\
\hline $\begin{array}{l}\text { Boiling point } \\
\text { dropped }\end{array}$ & $\begin{array}{c}\text { porosity } \\
\text { coating thickness } \\
\text { particle diameter } \\
\text { surface roughness } \\
\text { liquid density } \\
\text { specific heat } \\
\text { latent heat of vaporization } \\
\text { surface tension } \\
\text { liquid thermal conductivity } \\
\text { surface inclination } \\
\text { wall superheat }\end{array}$ & 0.966 & 18.643 \\
\hline $\begin{array}{l}\text { liquid thermal } \\
\text { conductivity dropped }\end{array}$ & $\begin{array}{c}\text { porosity } \\
\text { coating thickness } \\
\text { particle diameter } \\
\text { surface roughness } \\
\text { liquid density } \\
\text { specific heat } \\
\text { latent heat of vaporization } \\
\text { surface tension } \\
\text { boiling point } \\
\text { surface inclination } \\
\text { wall superheat }\end{array}$ & 0.981 & 17.019 \\
\hline $\begin{array}{c}\text { All liquid features } \\
\text { dropped }\end{array}$ & $\begin{array}{c}\text { porosity } \\
\text { coating thickness } \\
\text { particle diameter } \\
\text { surface roughness } \\
\text { surface inclination } \\
\text { wall superheat }\end{array}$ & 0.94 & 35.6 \\
\hline
\end{tabular}


Table 4. Cont.

\begin{tabular}{|c|c|c|c|}
\hline Model & Input Parameters & $\mathbf{R}^{2}$ & AARD \\
\hline $\begin{array}{l}\text { Surface inclination } \\
\text { dropped }\end{array}$ & $\begin{array}{c}\text { porosity } \\
\text { coating thickness } \\
\text { particle diameter } \\
\text { surface roughness } \\
\text { liquid density } \\
\text { specific heat } \\
\text { latent heat of vaporization } \\
\text { surface tension } \\
\text { boiling point } \\
\text { liquid thermal conductivity } \\
\text { wall superheat }\end{array}$ & 0.967 & 20.408 \\
\hline $\begin{array}{l}\text { Wall superheat } \\
\text { dropped }\end{array}$ & $\begin{array}{c}\text { porosity } \\
\text { coating thickness } \\
\text { particle diameter } \\
\text { surface roughness } \\
\text { liquid density } \\
\text { specific heat } \\
\text { latent heat of vaporization } \\
\text { surface tension } \\
\text { boiling point } \\
\text { liquid thermal conductivity } \\
\text { surface inclination }\end{array}$ & 0.893 & 30.079 \\
\hline
\end{tabular}

The choice of the pool boiling parameters is a very important aspect of this study. For instance, to predict the boiling heat transfer coefficient of engineered surfaces subjected to different working fluids of completely different thermophysical properties for a wide range of pool boiling conditions, it is extremely important to include the most influential parameters in the architecture of the model. This is the major limitation of the existing correlations in the literature-that these correlations cannot account for all of the important surface, liquid, and testing parameters, resulting in a very poor predictability for different surface liquid combinations and testing ranges. Other than considering the important surface and liquid features, the proposed model accounts for important pool boiling testing parameters. For example, in the proposed model, wall superheat and surface inclination angle were considered as the inputs. However, the predictions can be done by replacing the wall superheat with the applied heat flux. However, for the investigated data, the predictability of the model with the heat flux was relatively lower than the model with the wall superheat. Hence, wall superheat was chosen as the input parameter.

With the help of the proposed methodology, a highly accurate BHTC can be estimated by incorporating the strongly influencing liquid, surface, and pool boiling testing parameters into the Bayesian optimization-based neural network model. Owing to improved heat transfer performance, microporous surfaces are the prime candidate to remove the high heat fluxes generated through various applications. For instance, $3 \mathrm{M}$ copper powder is widely used in industry to form a boiling coated surface. These boiling surfaces can be used to cool microprocessors, LEDs, power electronics, MOSFETs and IGBTs. Other than that, sintered coated surfaces can be used to manufacture high-flux surfaces, employed to reduce plant size by decreasing the number of reboilers required in petrochemical plants.

\section{Conclusions}

The objective of this study is to develop Bayesian optimized deep neural network models to perform a sensitivity analysis for finding the most influential parameters in the boiling heat transfer assessment of sintered coated porous surfaces subjected to a variety of high- and low-wetting working fluids, including water, dielectric fluids, and refrigerants, under saturated pool boiling conditions and different surface inclination angles of the heater surface. Some of very specific conclusions are provided as follows. 
- The model with all the surface morphological features, liquid thermophysical properties, and pool boiling testing parameters demonstrates the highest $R^{2}=0.985$ for HTC prediction.

- The wall superheat is noted to have the maximum impact on the predictive accuracy of the boiling heat transfer coefficient. For example, if the wall superheat is dropped from the modeling parameters, the lowest prediction of $R^{2}(0.893)$ is achieved.

- The surface morphological features show relatively less influence compared to the liquid thermophysical properties, e.g., liquid thermophysical properties are much more sensitive to the pool boiling phenomenon of sintered coated porous surfaces compared to the morphology of the heater surfaces.

- Particle diameter showed the strongest influence on the heat transfer coefficient compared to the rest of the morphological parameters.

- The BHTC is strongly influenced by the surface inclination angle of the heater surface.

- By dropping the surface inclination angle from the modeled parameters, $R^{2}$ is reduced to 0.967 .

- The proposed methodology can be applied to a wider range of data in order to determine the highly influential surface and liquid parameters for boiling heat transfer assessment.

Author Contributions: Conceptualization, U.S.; data curation, U.S., I.H. and K.R.; formal analysis, U.S., I.H. and K.R.; funding acquisition, C.-C.W., K.R., S.M.S. and A.Y.E.; investigation, U.S., I.H., S.M., K.R. and E.E.H.; methodology, U.S. and I.H.; project administration, U.S., C.-C.W. and A.Y.E.; resources, S.M.S., A.Y.E. and E.E.H.; software, U.S., I.H. and S.M.; supervision, C.-C.W. and A.Y.E.; validation, I.H. and C.-C.W.; visualization, M.S., S.M. and E.E.H.; writing-original draft, U.S. and I.H.; writing-review and editing, M.S., K.R., S.M.S. and E.E.H. All authors have read and agreed to the published version of the manuscript.

Funding: This work was financially supported by the Ministry of Science and Technology, Taiwan under contracts 108-2221-E-009-058-MY3 and 109-2622-E-009-0015. This work was also financially supported by the Taif University Researchers Supporting Project No. TURSP-2020/32, Taif University, Taif, Saudi Arabia.

Institutional Review Board Statement: Not applicable.

Informed Consent Statement: Not applicable.

Data Availability Statement: Data are contained within the article.

Acknowledgments: This work was financially supported by the Taif University Researchers Supporting Project No. TURSP-2020/32, Taif University, Taif, Saudi Arabia. The authors are also indebted to the financial support from Ministry of science and technology, Taiwan under contracts 108-2221-E-009-058-MY3 and 109-2622-E-009-0015.

Conflicts of Interest: The authors declare no conflict of interest.

\section{References}

1. Sajjad, U.; Hussain, I.; Wang, C.-C. A high-fidelity approach to correlate the nucleate pool boiling data of roughened surfaces. Int. J. Multiph. Flow 2021, 142, 103719. [CrossRef]

2. Sajjad, U.; Sadeghianjahromi, A.; Ali, H.M.; Wang, C.-C. Enhanced pool boiling of dielectric and highly wetting liquids-A review on surface engineering. Appl. Therm. Eng. 2021, 195, 117074. [CrossRef]

3. Sajjad, U.; Sadeghianjahromi, A.; Ali, H.M.; Wang, C.-C. Enhanced pool boiling of dielectric and highly wetting liquids-a review on enhancement mechanisms. Int. Commun. Heat Mass Transf. 2020, 119, 104950. [CrossRef]

4. Sajjad, U.; Sadeghianjahromi, A.; Wang, C.-C. Enhancing Boiling Heat Transfer for Electronics Cooling by Embedding an Array of Microgrooves into Sandblasted Surfaces. Heat Trans. Res. 2021, 52, 71-89. [CrossRef]

5. Tran, N.; Sajjad, U.; Lin, R.; Wang, C.-C. Effects of surface inclination and type of surface roughness on the nucleate boiling heat transfer performance of HFE-7200 dielectric fluid. Int. J. Heat Mass Transf. 2020, 147, 119015. [CrossRef]

6. Manetti, L.L.; Ribatski, G.; de Souza, R.R.; Cardoso, E.M. Pool boiling heat transfer of HFE-7100 on metal foams. Exp. Therm. Fluid Sci. 2020, 113, 110025. [CrossRef]

7. Sajjad, U.; Wang, C.-C. Nucleate pool boiling of high flux sintered coated porous surfaces with dielectric liquid, HFE-7200. J. Enhanc. Heat Transf. 2020, 27, 767-784. [CrossRef] 
8. Pastuszko, R.; Wójcik, T.M. Experimental investigations and a simplified model for pool boiling on micro-fins with sintered perforated foil. Exp. Therm. Fluid Sci. 2015, 63, 34-44. [CrossRef]

9. Halon, T.; Zajaczkowski, B.; Michaie, S.; Rulliere, R.; Bonjour, J. Enhanced tunneled surfaces for water pool boiling heat transfer under low pressure. Int. J. Heat Mass Transf. 2018, 116, 93-103. [CrossRef]

10. Jaikumar, A.; Kandlikar, S.G. Enhanced pool boiling heat transfer mechanisms for selectively sintered open microchannels. Int. J. Heat Mass Transf. 2015, 88, 652-661. [CrossRef]

11. Xu, Z.; Qu, Z.; Zhao, C.; Tao, W. Pool boiling heat transfer on open-celled metallic foam sintered surface under saturation condition. Int. J. Heat Mass Transf. 2011, 54, 3856-3867. [CrossRef]

12. Jun, S.; Kim, J.; Son, D.; Kim, H.Y.; You, S.M. Enhancement of pool boiling heat transfer in water using sintered copper microporous coatings. Nucl. Eng. Technol. 2016, 48, 932-940. [CrossRef]

13. Mo, D.-C.; Yang, S.; Luo, J.-L.; Wang, Y.-Q.; Lyu, S.-S. Enhanced pool boiling performance of a porous honeycomb copper surface with radial diameter gradient. Int. J. Heat Mass Transf. 2020, 157, 119867. [CrossRef]

14. Pastuszko, R.; Kaniowski, R.; Wójcik, T.M. Comparison of pool boiling performance for plain micro-fins and micro-fins with a porous layer. Appl. Therm. Eng. 2020, 166, 114658. [CrossRef]

15. Sajjad, U.; Hussain, I.; Hamid, K.; Bhat, S.A.; Ali, H.M.; Wang, C.-C. A deep learning method for estimating the boiling heat transfer coefficient of porous surfaces. J. Ther. Anal. Calorim. 2021, 145, 1911-1923. [CrossRef]

16. Ahmad, S.W.; Lewis, J.S.; McGlen, R.J.; Karayiannis, T.G. Pool boiling on modified surfaces using R-123. Heat Transf. Eng. 2014, 35, 1491-1503. [CrossRef]

17. Dabek, L.; Kapjor, A.; Orman, Ł.J. Distilled water and ethyl alcohol boiling heat transfer on selected meshed surfaces. Mech. Ind. 2019, 20, 701. [CrossRef]

18. Deng, D.; Wan, W.; Feng, J.; Huang, Q.; Qin, Y.; Xie, Y. Comparative experimental study on pool boiling performance of porous coating and solid structures with reentrant channels. Appl. Therm. Eng. 2016, 107, 420-430. [CrossRef]

19. Dewangan, A.K.; Kumar, A.; Kumar, R. Experimental study of nucleate pool boiling of R-134a and R-410A on a porous surface. Heat Transf. Eng. 2019, 40, 1249-1258. [CrossRef]

20. Gupta, S.K.; Misra, R.D. Development of micro/nanostructured-Cu- $\mathrm{TiO}_{2}$-nanocomposite surfaces to improve pool boiling heat transfer performance. Heat Mass Transf. 2020, 56, 2529-2544. [CrossRef]

21. Hu, Y.; Zhang, S.; Li, X.; Wang, S. Heat transfer enhancement of subcooled pool boiling with self-rewetting fluid. Int. J. Heat Mass Transf. 2015, 83, 64-68. [CrossRef]

22. Jun, S.; Kim, J.; You, S.M.; Kim, H.Y. Effect of subcooling on pool boiling of water from sintered copper microporous coating at different orientations. Sci. Technol. Nucl. Install. 2018, 2018, 8623985. [CrossRef]

23. Li, C.; Peterson, G. Evaporation/Boiling in Thin Capillary Wicks (II)—Effects of Volumetric Porosity and Mesh Size. ASME J. Heat Transfer. 2006, 128, 1320-1328. [CrossRef]

24. Li, C.; Peterson, G. Parametric Study of Pool Boiling on Horizontal Highly Conductive Microporous Coated Surfaces. ASME J. Heat Transfer. 2007, 129, 1465-1475. [CrossRef]

25. Liu, F. A Study of Sintered Copper Porous Surfaces for Pool Boiling Enhancement. Rochester Institute of Technology. ProQuest Dissertations Publishing, 2016; p. 10248320. Available online: https:/ /www.proquest.com/openview/aa59d1b109e23f558dc5d1 6aeee8f927 /1?pq-origsite $=$ gscholar\&cbl=18750 (accessed on 27 September 2021).

26. McHale, J.P.; Garimella, S.V.; Fisher, T.S.; Powell, G.A. Pool boiling performance comparison of smooth and sintered copper surfaces with and without carbon nanotubes. Nanoscale Microscale Thermophys. Eng. 2011, 15, 133-150. [CrossRef]

27. Mori, S.; Aznam, S.M.; Okuyama, K. Enhancement of the critical heat flux in saturated pool boiling of water by nanoparticlecoating and a honeycomb porous plate. Int. J. Heat Mass Transf. 2015, 80, 1-6. [CrossRef]

28. Nasersharifi, Y.; Kaviany, M.; Hwang, G. Pool-boiling enhancement using multilevel modulated wick. Appl. Therm. Eng. 2018, 137, 268-276. [CrossRef]

29. Rahimian, A.; Kazeminejad, H.; Khalafi, H.; Akhavan, A.; Mirvakili, S.M. Boiling Heat Transfer and Critical Heat Flux Enhancement Using Electrophoretic Deposition of $\mathrm{SiO}_{2}$ Nanofluid. Sci. Technol. Nucl. Install. 2019, 2019, 1272156. [CrossRef]

30. Rioux, R.P.; Nolan, E.C.; Li, C.H. A systematic study of pool boiling heat transfer on structured porous surfaces: From nanoscale through microscale to macroscale. AIP Adv. 2014, 4, 117133. [CrossRef]

31. Sarangi, S.; Weibel, J.A.; Garimella, S.V. Effect of particle size on surface-coating enhancement of pool boiling heat transfer. Int. J. Heat Mass Transf. 2015, 81, 103-113. [CrossRef]

32. Wen, M.-Y.; Ho, C.-Y.; Jang, K.-J. An optimal parametric design to improve pool boiling heat transfer of sintered surfaces. J. Eng. Technol. Res. 2012, 4, 49-56.

33. Xu, H.; Dai, Y.; Cao, H.; Liu, J.; Zhang, L.; Xu, M.; Cao, J.; Xu, P.; Liu, J. Tubes with coated and sintered porous surface for highly efficient heat exchangers. Front. Chem. Sci. Eng. 2018, 12, 367-375. [CrossRef]

34. Zhang, K.; Bai, L.; Lin, G.; Jin, H.; Wen, D. Experimental study on pool boiling in a porous artery structure. Appl. Therm. Eng. 2019, 149, 377-384. [CrossRef]

35. Asfahan, H.M.; Sajjad, U.; Sultan, M.; Hussain, I.; Hamid, K.; Ali, M.; Wang, C.-C.; Shamshiri, R.R.; Khan, M.U. Artificial intelligence for the prediction of the thermal performance of evaporative cooling systems. Energies 2021, 14, 3946. [CrossRef]

36. Hamid, K.; Sajjad, U.; Yang, K.S.; Wu, S.-K.; Wang, C.-C. Assessment of an energy efficient closed loop heat pump dryer for high moisture contents materials: An experimental investigation and AI based modelling. Energy 2022, 238, 121819. [CrossRef] 
37. Chang, J.Y.; You, S.M. Boiling heat transfer phenomena from microporous and porous surfaces in saturated FC-72. Int. J. Heat Mass Transf. 1997, 40, 4437-4447. [CrossRef]

38. Jakob, M. Heat Transfer; John Wiley \& Sons: New York, NY, USA, 1949.

39. Pioro, I.L.; Rohsenow, W.; Doerffer, S.S. Nucleate pool-boiling heat transfer. I: Review of parametric effects of boiling surface. Int. J. Heat Mass Transf. 2004, 47, 5033-5044. [CrossRef]

40. Berenson, P.J. Experiments on pool-boiling heat transfer. Int. J. Heat Mass Transf. 1962, 5, 985-999. [CrossRef] 